\title{
vPARP Adjusts MVP Expression in Drug-resistant Cell Lines in Conjunction with MDR Proteins
}

\author{
KAROLINA WOJTOWICZ ${ }^{1}$, RADOSLAW JANUCHOWSKI ${ }^{1}$, MICHAL NOWICKI $^{1}$ and MACIEJ ZABEL ${ }^{1,2}$ \\ ${ }^{1}$ Department of Histology and Embryology, Poznan University of Medical Sciences, Poznan, Poland; \\ ${ }^{2}$ Department of Histology and Embryology, Wroclaw Medical University, Wroclaw, Poland
}

\begin{abstract}
Background/Aim: The definition of vault (ribonucleoprotein particles) function remains highly complex. Vaults may cooperate with multidrug resistance $(M D R)$ proteins, supporting their role in drug resistance. This topic is the main theme of this publication. Materials and Methods: The cell viability was determined by an MTT assay. The protein expression was detected by western blot analysis. The proteins were knocked-down using siRNA. Results: No major vault protein (MVP) in the LoVo/Dx and $W 1 P R$ cell lines after tunicamycin treatment was shown. In WIPR cells with knocked-down MVP, a statistically significant decrease in cell viability was noted. In LoVo/Dx, WITR and A2780TR cells were vault poly-ADP-ribose polymerase (vPARP) was knockdown, a decrease in cell viability was shown. Also, MVP silencing induced an increase in glycoprotein $P$ (Pgp) expression in LoVo/Dx cells. Conclusion: MVP is important for the drug resistance of cancer cells, but it probably requires the presence of $\checkmark P A R P$ for full activation. Some correlations between MDR proteins and vaults exist.
\end{abstract}

Vault particles are the largest ribonucleoprotein particles that have been discovered in human cells $(1,2)$. These unique cellular organelles have a barrel-shaped structure $(3,4)$ with overall dimensions of $71.5 \mathrm{~nm} \times 41 \mathrm{~nm} \times 41 \mathrm{~nm}$ and a mass of $13 \mathrm{MDa}$, making them the largest cytosolic nucleoprotein particles ever described $(5,6,7)$. Vaults are organized into two identical moieties, each consisting of 39 copies of the major vault protein (MVP) (1). Additionally, they contain two vault-associated proteins, vault poly-ADP-ribose

Correspondence to: Karolina Wojtowicz, Department of Histology and Embryology, Poznan University of Medical Sciences, Poznan, Poland. Tel: +48618546457, e-mail: k_wojtowicz@onet.pl

Key Words: Vaults, multidrug resistance, brefeldin A, castanospermine, tunicamycin, chemotherapy, glycoprotein $\mathrm{P}$, BCRP. polymerase (vPARP) and telomerase associated protein 1 (TEP1) $(1,5)$ as well as several small non-coding RNAs (vRNAs) (8).

The 100-110 kDa MVP represents more than $70 \%$ of the vault mass (5). MVP expression levels allow for formation of up to 105 vaults per mammalian cell, and these levels seem to be regulated strictly. Diverse MVP expression has been described in chemotherapy-resistance conditions (5). Also, the protein vPARP, with a molecular mass of $193 \mathrm{kDa}$, is only partly associated with vaults (5) and is present in the cytoplasm and nucleus (9). The copy number of vPARP estimations has ranged from 4 to 16 copies. Furthermore, vPARP is catalytically active both within the vault complex and as a single molecule (5). The presence of MVP strongly enhances the half-life of vPARP, proving that other vault components have an impact on the vault reservoir (5). The significance of vPARP activity for vault function is not yet known. The other protein interacting with vault is the 240-kDa TEP1 protein (9). Scientists noticed two to four copies of TEP1 per vault (5). The protein was also found to be associated with the telomerase complex. Within the telomerase complex, the function of TEP1 remains unknown (10). The last vault component is RNA. Although the class of vault RNAs was initially identified almost 30 years ago, its function is not yet completely clear. The stoichiometric model of the vault particle proposes that it contains at least six copies of vRNA (11).

Some data have shown that vault particles are capable of rapidly separating and returning to whole vaults structure (12). This fact suggests that vaults can interact with their cellular environment and deliver materials packaged within their interiors (12). Scientists have suggested possible functions of vaults including their role in transport processes so that vaults can be utilized as natural nanocapsules for drug, nucleic acid, or protein delivery $(1,5,13)$. MVP was found to be orthologous to the well-known human lung resistance-related protein LRP, combining MVP function with drug resistance $(1,14)$. Furthermore, MVP is generally overexpressed in drug-resistant human cancer cells and could 
be causally involved in the associated resistance phenotype $(5,9,15)$. It was suggested that up-regulation of all vault components was necessary for vault-mediated MDR (8). MVP and, by extension, vault complexes are important for lysosomal function and might influence cellular drug resistance owing to this role (13). However, most suggestions have indicated that MVP and vaults are not directly involved in resistance to cytostatic drugs (16) and could, for instance, function through other mechanisms, such as intracellular sequestration (13).

Despite a growing amount of data from diverse species and systems, the definition of vault function remains highly complex and challenging. Interestingly, it might be that vaults cooperate with MDR proteins, supporting the role of the latter in the drug resistance of cancer cell lines (10). This topic was the main theme of this study. We wanted to analyse whether inhibitors of $\mathrm{N}$-glycosylation, which destroy MDR expression and function $(17,18)$, activate another defence mechanism in cancer cells connected to vaults. We focused on the most important MDR proteins, which are Pglycoprotein (Pgp) and breast cancer resistance protein (BCRP) (19). The role of Pgp in MDR was first described in 1987 by Pastan and Gottesman (20). Human Pgp contains three sequences that are glycosylated and that seem to be related to their drug resistance function (21). BCRP, the other drug transporter protein, was also implicated in the development of the MDR phenotype, and it was reported to be overexpressed in many solid tumours (22). The BCRP $N$ linked glycosylation sites corresponded to Asn596 in the extracellular loop (23). Our data suggested that inhibition of the glycosylation of this protein led to blockage of its activity, so these compounds are likely to be useful as supplements in anticancer therapy $(17,18)$.

\section{Materials and Methods}

Chemicals and drugs. Doxorubicin (dox), topotecan (top), paclitaxel (pac), tunicamycin (TUN), brefeldin A (BFA), castanospermine (CAS) and RIPA Lysis Buffer were obtained from Sigma (St. Louis, MO, USA). RPMI-1640 and MEME, foetal bovine serum (FBS), antibiotic-antimycotic solution, and L-glutamine were also purchased from Sigma (St. Louis, MO, USA). Bradford Dye Reagent was obtained from Bio-Rad Laboratories (Hemel Hempstead, UK). Nitrocellulose membranes were obtained from Bio-Rad Laboratories (Hemel Hempstead, UK). The Cell Proliferation Kit I (MTT) and protease inhibitor cocktail were purchased from Roche Diagnostics GmbH (Mannheim, Germany). The rabbit anti-ABCG2 polyclonal $\mathrm{Ab}(\mathrm{H}-70)$ used for $\mathrm{WB}$, rabbit anti-GADPH polyclonal Ab (FL-335), goat anti-mouse HRPconjugated $\mathrm{Ab}$, and goat anti-rabbit HRP-conjugated $\mathrm{Ab}$ were purchased from Santa Cruz Biotechnology (Santa Cruz, CA, US). Mouse monoclonal anti-P-glycoprotein Ab (C219) was obtained from Alexis Biochemicals (Lörrach, Germany). Mouse monoclonal anti-MVP was obtained from Enzo Life Sciences (Lörrach Germany), and rabbit monoclonal anti-vPARP was obtained from
Abcam (Cambridge, UK). Rabbit polyclonal anti-TEP1 was obtained from Novus Biologicals (Germany). The 4x Laemmli sample buffer and 4-20\% mini-PROTEAN ${ }^{\circledR}$ TGX $^{\mathrm{TM}}$ precast gels were obtained from Bio-Rad Laboratories (Hemel Hempstead, UK).

Cell culture. Two resistant ovarian cancer cell lines were used in this study. From the W1 (primary ovarian cancer cell line, established from ovarian cancer tissues that were obtained from an untreated patient in December 2009 [these cell lines were derived in our laboratory as described previously by Januchowski (24), we generated the W1TR subline, which is resistant to top (in a top concentration of $24 \mathrm{ng} / \mathrm{ml}$ ), and the W1PR subline, which is resistant to pac (in a pac concentration of $1100 \mathrm{ng} / \mathrm{ml}$ ). The second ovarian cancer cell line, A2780TR, is a top-resistant subline that was generated from the commercially available established human ovarian carcinoma cell line A2780 (obtained from ATCC, VA, USA). The drug-resistant sublines were generated by the exposure of drug-sensitive cells to incrementally higher concentrations of each drug. The human colon adenocarcinoma LoVo and its doxorubicin-resistant subline LoVo/Dx were also used (obtained from ATCC, VA, USA). LoVo/Dx was cultured in the presence of $200 \mathrm{ng} / \mathrm{ml}$ dox.

The LoVo, LoVo/Dx, A2780 and A2780TR cell lines were cultured in MEME, and the W1, W1PR and W1TR cell lines were cultured in RPMI-1640. The media were supplemented with $10 \%$ FBS, $2 \mathrm{mM}$ L-glutamine and $1 \%$ antibiotic-antimycotic solution. The cells were cultured at $37^{\circ} \mathrm{C}$ in a humidified atmosphere with $5 \% \mathrm{CO}_{2}(\mathrm{v} / \mathrm{v})$.

The W1TR and A2780TR cells have been shown to overexpress BCRP, while the W1PR and LoVo/Dx cells overexpress Pgp (24, $25,26,27)$.

MVP, TEP1 and $v P A R P$ silencing. We knocked-down the protein components of vaults using small interfering RNA (siRNA) (Life Technologies, MA, USA) according to the manufacturer's protocol. Before silencing, the cells were seeded $(250000$ cells/well of a 6 well plate) and pre-incubated for $24 \mathrm{~h}$. On the following day, target siRNA was added. After $72 \mathrm{~h}$, cells were collected and prepared for the subsequent experiments.

We used western blot analysis to verify the silencing effectiveness.

Preparation of cell lysates. To determine vault protein and MDR protein expression in cells treated with inhibitors and untreated cells, we performed an immunoblot analysis. The cells were pre-incubated for $48 \mathrm{~h}\left(1 \times 10^{6}\right.$ cells $/ 75 \mathrm{~cm}^{2}$ culture flask $)$. The medium was then replaced with fresh medium only or fresh medium supplemented with TUN, BFA or CAS at predetermined concentrations $(17,18)$. After $72 \mathrm{~h}$ of incubation, the cells were harvested by trypsinization and pelleted by centrifugation. The cell pellets were washed once with phosphate-buffered saline (PBS), and lysed with RIPA lysis buffer supplemented with protease inhibitor cocktail for 5 min on ice. The cell lysates were centrifuged at $8000 \mathrm{~g}$ at $4^{\circ} \mathrm{C}$ for $10 \mathrm{~min}$, and the total protein concentration in the supernatant was measured. The protein concentration was determined using Bradford Dye Reagent with BSA as the standard.

To determine vault protein and MDR protein expression in cells after siRNA treatment, we pre-incubated cells with fresh medium for $24 \mathrm{~h}$ after silencing (6-well plate). After this time, we collected the control lysates to assess the efficiency of gene silencing. In this 
example, we used lysis buffer containing $20 \mathrm{mM}$ Tris and $2 \%$ SDS with a $\mathrm{pH}$ of 7.5. After slight heating of the cells suspended in lysis buffer, we collected the liquid part of the sample, which was then heated to $95^{\circ} \mathrm{C}$ for 10 minutes. Next, ice cold acetone was added, and the samples were incubated at $-20^{\circ} \mathrm{C}$ overnight. On the following day, to obtain proteins, we centrifuged the samples at 8 $000 \mathrm{~g}$ at $4^{\circ} \mathrm{C}$ for $10 \mathrm{~min}$. The pellets were mixed with $40 \mu \mathrm{l}$ of $2 \mathrm{x}$ Laemmli sample buffer.

Western blot analysis. Western blot analysis was conducted under reducing conditions. The cell lysate samples prepared with RIPA buffer $(35 \mu \mathrm{g})$ were first mixed with $4 \mathrm{x}$ Laemmli sample buffer and were incubated at RT for $20 \mathrm{~min}$. However, the cell lysate samples that were prepared using lysis buffer, containing $20 \mathrm{mM}$ Tris and $2 \% \mathrm{SDS}$ at a $\mathrm{pH}$ of 7.5 , were directly applied to the gel $(10 \mu \mathrm{l} / \mathrm{well})$. The lysates were electrophoretically separated on a $4-20 \%$ miniPROTEAN ${ }^{\circledR}$ TGX $^{\mathrm{TM}}$ precast gel and electroblotted onto a nitrocellulose membrane. The membrane was blocked with $5 \%$ (w/v) dry milk in TBS at RT for $1 \mathrm{~h}$. The membranes were then incubated with anti-Pgp, anti-BCRP, anti-MVP, anti-vPARP primary (1:500 dilution) and anti-TEP1 (1:1000 dilution) at $4^{\circ} \mathrm{C}$ overnight. The membranes were also probed with anti-GAPDH antibody (1:1000 dilution) as a loading control. For the secondary antibody, horseradish peroxidase (HRP)-linked anti-species antibody was used at a dilution of 1:2 000. HRP-dependent luminescence was developed with Femto Super Signal Reagent (Thermo Scientific, MA, USA) and was detected using a UVP Imaging System.

The TUN concentration used was based on the following previously established values for each cell line: $60 \mathrm{ng} / \mathrm{ml}$ for LoVo/Dx, $30 \mathrm{ng} / \mathrm{ml}$ for W1PR and W1TR and $40 \mathrm{ng} / \mathrm{ml}$ for A2780TR (9); for BFA: $10 \mathrm{ng} / \mathrm{ml}$ for LoVo/Dx, $7 \mathrm{ng} / \mathrm{ml}$ for W1PR, $6 \mathrm{ng} / \mathrm{ml}$ for W1TR and $8 \mathrm{ng} / \mathrm{ml}$ for A2780TR; and for CAS: $10 \mu \mathrm{g} / \mathrm{ml}$ for LoVo/Dx, $50 \mu \mathrm{g} / \mathrm{ml}$ for W1PR and W1TR, and 60 $\mu \mathrm{g} / \mathrm{ml}$ for A2780TR (10).

Cell viability assay. To determine the cell viability, we used a cell proliferation kit (MTT) according to the manufacturer's instructions. A survival assay was performed to estimate the extent of cell resistance to the chemotherapeutic agents after silencing of vault compartments. After vault component silencing, the cells were seeded at $4 \times 10^{3}$ cells per well $(200 \mu \mathrm{l})$ in 96 -well culture plates and were pre-incubated for $24 \mathrm{~h}$. To examine the effects of chemotherapeutic drugs on cell survival, the cells were treated in established concentrations with different drugs for $72 \mathrm{~h}$. Subsequently, $10 \mu \mathrm{l}$ of MTT labelling reagent was added to the medium (the final concentration of MTT was $0.5 \mathrm{mg} / \mathrm{ml}$ ) for $4 \mathrm{~h}$, and $100 \mu \mathrm{l}$ of the solubilized solution was then added to each well. After an overnight incubation, the absorbance was measured in a microplate reader at $570 \mathrm{~nm}$ with a reference wavelength of $720 \mathrm{~nm}$. All of the experiments were repeated three times.

Statistical analysis. The statistical analysis was performed using Microsoft Excel software. The statistical significance of the differences was determined by applying Student's $t$-test. $p$-Values of 0.05 or less were considered statistically significant.

\section{Results}

Effects of inhibitors of $N$-glycosylation on vault and MDR protein expression. Western blot analysis was used to check vault particle and MDR protein expression in the tested cell lines. We analysed protein expression in sensitive cell lines, their resistant versions and resistant cell lines treated with inhibitors of $N$-glycosylation.

Figure 1 presents the results obtained for the following cell lines characterized by Pgp overexpression: LoVo/Dx and W1PR. The LoVo and W1 sensitive cell lines represented a negative control for Pgp expression. In LoVo cells, we observed the expression of TEP1 and low levels of MVP expression but no expression of vPARP. The LoVo/Dx cell line has been characterized by the presence of $170 \mathrm{kDa}$ Pgp and all vault particles. Furthermore, in LoVo/Dx cells, the MVP expression was higher than in the LoVo cell line. In LoVo/Dx pretreated with BFA and CAS, the vault expression was the same as in LoVo/Dx. However, in TUN-treated LoVo/Dx cells, no vault proteins were observed. Furthermore, in the TUN-treated LoVo/Dx cells, we observed that Pgp had a molecular mass of $70 \mathrm{kDa}$, which is in accordance with our previous results (17). The primary ovarian cancer cell line W1 showed only MVP protein expression. The W1PR cell line was characterized by expression of Pgp and MVP but not other vaults protein. After incubation of W1PR cells with BFA and CAS, we did not observe changes in MVP expression. Treatment with TUN led to the lack of MVP expression in the W1PR cell line. Additionally, in the TUN-treated W1PR cells, we observed Pgp expression with a molecular mass of $70 \mathrm{kDa}$.

Figure 2 presents the expression of vault proteins and BCRP proteins in the following cell lines characterized by BCRP overexpression: A2780TR and W1TR. As a control, we used the parental drug-sensitive A2780 cell line. Both cell lines, A2780 and A2780TR, were characterized by MVP, TEP1 and vPARP expression. In the A2780TR cell line, we observed lower levels of MVP and TEP1 proteins than in the A2780 drug-sensitive cell line. In contrast, expression of vPARP was increased in the A2780TR cell line. Despite the inhibitors of $N$-glycosylation used in A2780TR cells, we did not notice any changes in MVP and TEP1 expression. The A2780TR cells pre-treated with inhibitors presented an increase in vPARP expression. The A2780TR cells treated with BFA were characterized by the presence of an additional, degraded form of BCRP protein, and CAS treatment induced a higher amount of nonglycosylated BCRP; however, TUN treatment completely blocked BCRP expression. In W1TR cells, we observed expression of all vault proteins. After treatment of W1TR cells with inhibitors of $N$-glycosylation, we observed decreased TEP1 expression. Furthermore, CAS treatment of W1TR cells influenced a decrease in MVP and vPARP expression. The W1TR cells treated with BFA were characterized by the presence of an additional, degraded form of BCRP protein; the CAS and TUN treatment induced a higher amount of non-glycosylated BCRP. 


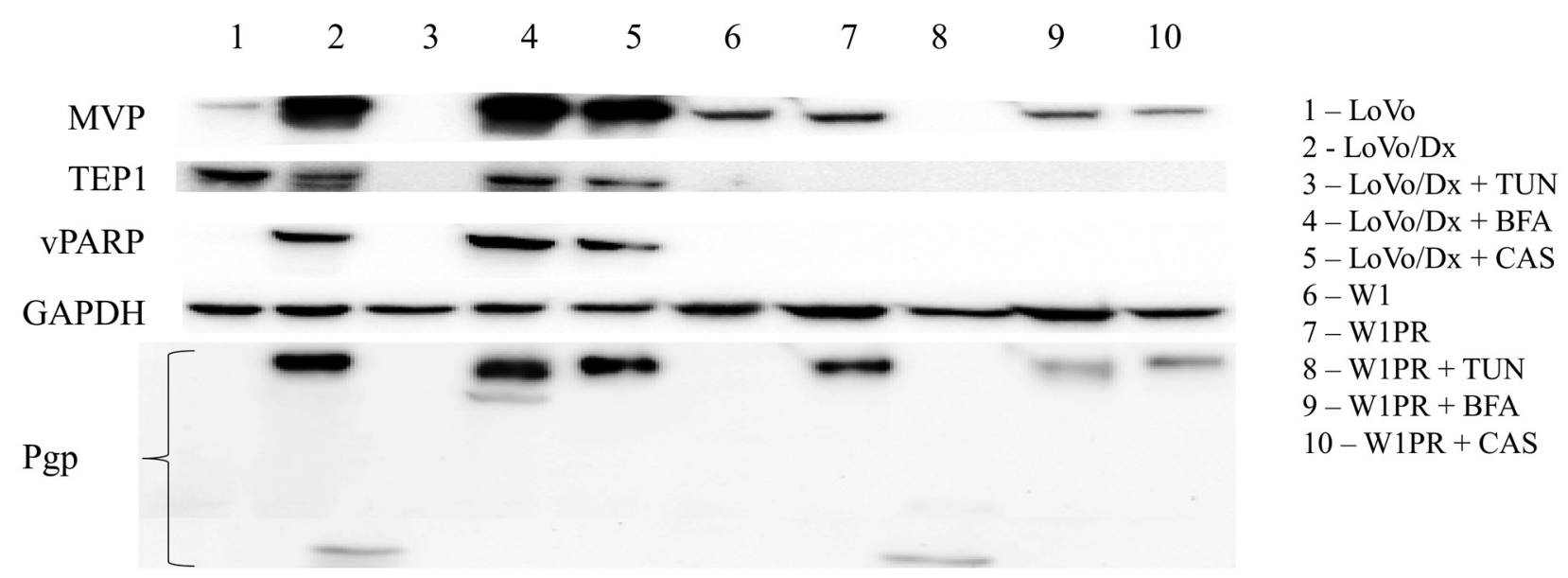

Figure 1. Effects of TUN, BFA and CAS on the expression of MVP, TEP1, vPARP and Pgp proteins in the LoVo/Dx and W1PR cell lines. As a control, we used protein lysate from LoVo and W1 cells. Cellular proteins $(35 \mu \mathrm{g})$ were separated on a $4-20 \%$ mini-PROTEAN ${ }^{\circledR}$ TGX ${ }^{T M}$ precast gel and were transferred to a nitrocellulose membrane. The membrane was blocked and immunoblotted with a primary Ab and then an HRP-conjugated secondary Ab. GAPDH was used as a loading control for the western blot analysis.

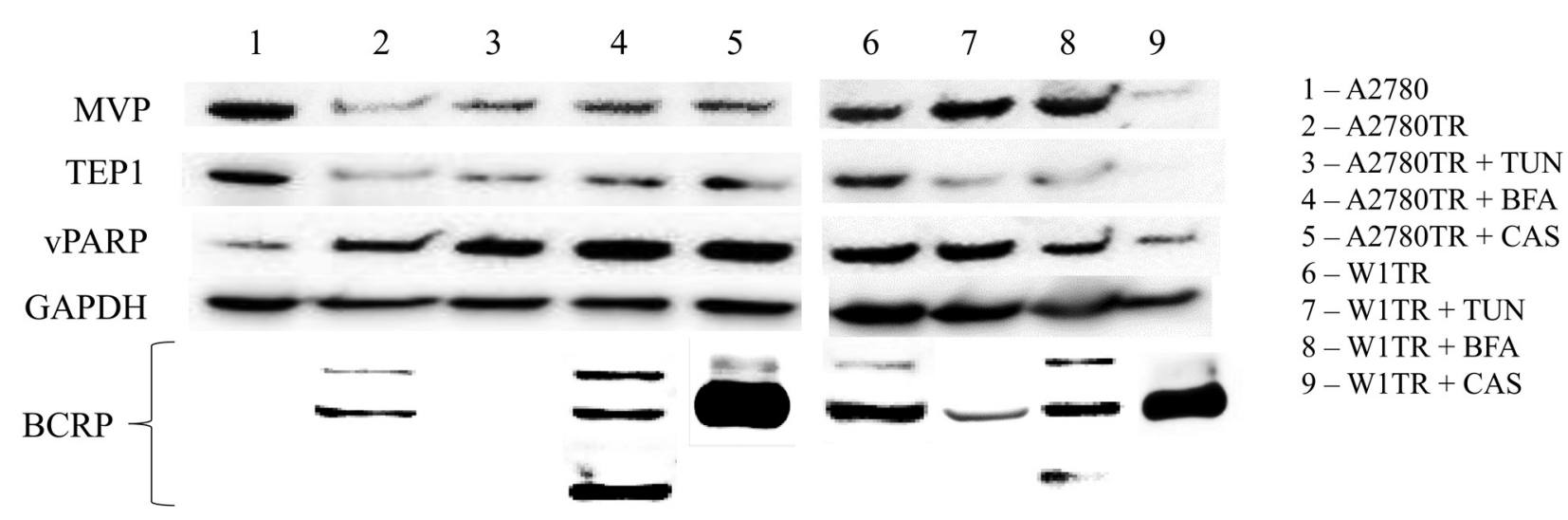

Figure 2. Effects of TUN, BFA and CAS on the expression of MVP, TEP1, vPARP and BCRP proteins in the A2780TR and W1TR cell lines. As a control, we used the protein lysate from A2780 cells. The cellular proteins $(35 \mu \mathrm{g})$ were separated on a $4-20 \%$ mini-PROTEAN ${ }^{\circledR}$ TGX ${ }^{T M}$ precast gel and were transferred to a nitrocellulose membrane. The membrane was blocked and immunoblotted with a primary Ab and then an HRPconjugated secondary Ab. GAPDH was used as a loading control for the western blot analysis.

siRNA is effective in MVP, TEPI and $v P A R P$ silencing. In the next step, we wanted to analyse the effectiveness and durability of the knocking down of vault particles. We knocked down the relevant proteins whose expression was observed in each cell line (Figures 1 and 2). The genes were knocked down for $72 \mathrm{~h}$; after another $24 \mathrm{~h}$ of incubation with fresh medium, the lysates were prepared. In all four parts of Figure 3, we show the results for the control sample, sample in which we used target siRNA, and serial dilutions of the samples that were treated with non-target siRNA (sample $100 \%, 75 \%, 50 \%$ and $25 \%$ ). As a result, we were able to estimate the degree of silencing. Part A (Figure 3) shows that, in the W1PR cell line, MVP silencing was one-hundred percent effective. Part $\mathrm{C}$ in Figure 3 shows that, in the W1TR cell line, vPARP silencing was fully effective, but MVP silencing was not as efficient. In contrast, we did not observe changes in the TEP1 expression after the use of siRNA. Furthermore, in the W1TR cell line, MVP and 
A W1PR

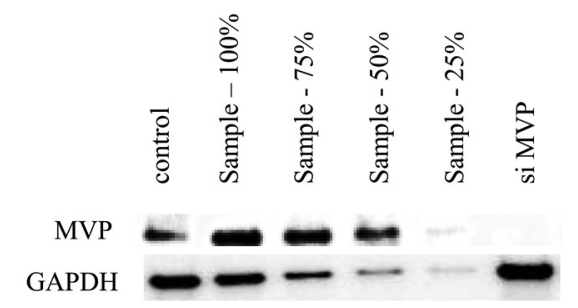

B

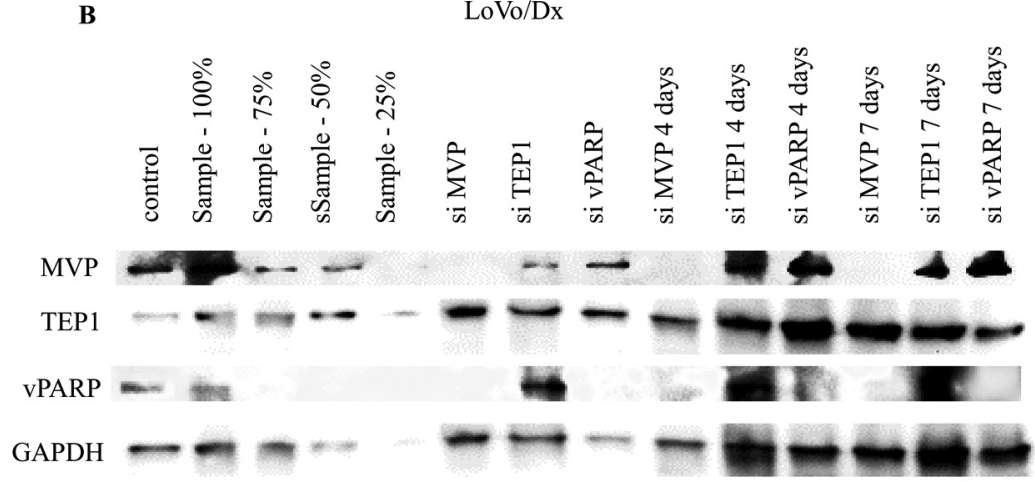

C



D

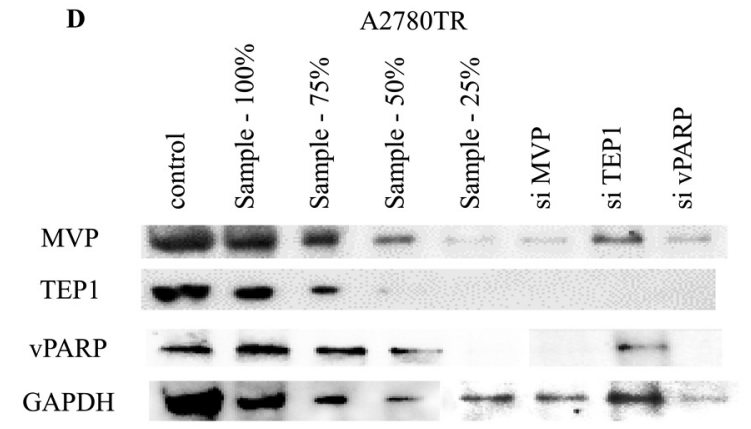

Figure 3. Effects of knocking-down of vault particles on the expression of MVP, TEP1 and VPARP proteins in the W1PR, LoVo/Dx, WITR and A2780TR cell lines. The cells were knocked down for $72 \mathrm{~h}$, and after another $24 \mathrm{~h}$ of incubation with fresh medium, the lysates were prepared. Cellular proteins were separated on a 4-20\% mini-PROTEAN ${ }^{\circledR} T G X^{T M}$ precast gel and were transferred to a nitrocellulose membrane. The membrane was blocked and immunoblotted with a primary $A b$ and then an HRP-conjugated secondary Ab. Part A. MVP expression in W1PR cells before and after MVP silencing. Part B. MVP, TEP1 and vPARP expression in LoVo/Dx cells before and after MVP, TEP1 and vPARP silencing. The effects of knockdown four and seven days after silencing. Part C. MVP, TEP1 and vPARP expression in W1TR cells before and after MVP, TEP1 and vPARP silencing. Part D. MVP, TEP1 and vPARP expression in A2780TR cells before and after MVP, TEP1 and vPARP silencing. GAPDH was used as a loading control for the western blots. Serial dilutions of the samples treated with non-target siRNA (sample -100\%, 75\%, 50\% and 25\%) were prepared to estimate the degree of silencing.

vPARP expression decreased regardless of the type of siRNA used. In A2780TR cells, MVP and vPARP were knocked down (Figure 3, part D), but in both examples, knocking down of one protein resulted in downregulation of the expression of the other protein. In the A2780TR cell line, TEP1 protein expression was not observed in cells supplemented with small interfering RNA nor in those supplemented with si TEP1, si MVP or si vPARP. Part B (Figure 3) shows that, in LoVo/Dx, MVP and vPARP were fully knocked down, but TEP1 expression was observed instead of the si TEP1 used. In LoVo/Dx cells, vPARP knockdown was correlated with simultaneous partial downregulation of MVP expression.

To verify the durability of the knocking down of vault particles, we also assessed protein expression four and seven days after silencing. In part B of Figure 3, we show that si MVP and si vPARP were efficient even seven days after knockdown.
Effect of vault particle silencing on drug cytotoxicity. We checked whether the knocking down of vault proteins had any effect on cell viability. For this reason, the cells were treated for $72 \mathrm{~h}$ with target siRNA. Next, the medium was changed, and the cells grew for $24 \mathrm{~h}$ in fresh medium. Cells were then incubated in the presence of drugs (paclitaxel/topotecan/doxorubicin) in the previously established concentrations (data not shown) for $72 \mathrm{~h}$.

The final results are presented as the viability ratio of the cells treated with siRNA, compared to the viability of the control cells (without siRNA) (Figure 4). Figure 4 shows that MVP knockdown did not influence the viability of cells treated with drugs (doxorubicin/topotecan) among the LoVo/Dx, W1TR and A2780TR cells. We noted that only MVP knockdown in W1PR cells led to a statistically significant reduction in cell viability (Figure 4). The vPARP knockdown decreased viability (almost statistically significant) in LoVo/Dx cells. The experiment also 
A

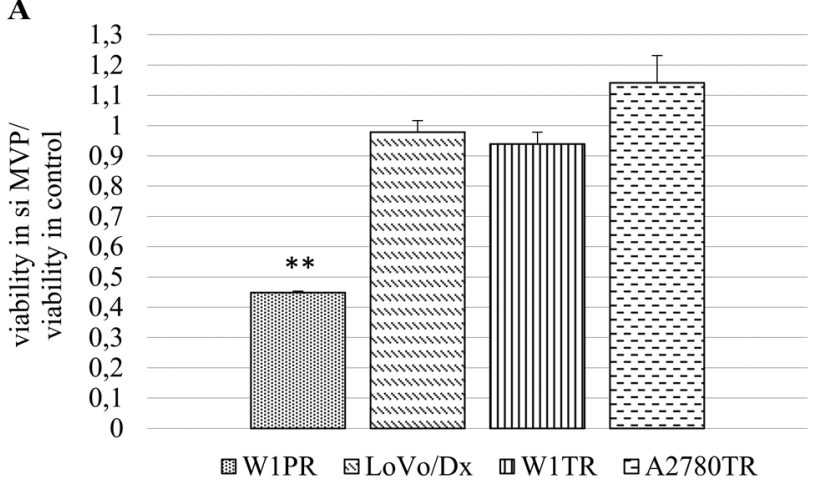

B

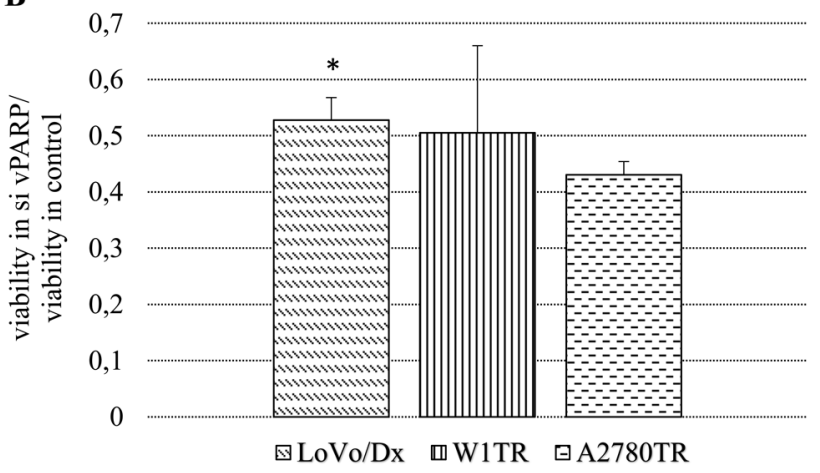

Figure 4. The viability ratio of the cells treated with siRNA, compared to the control cells. The cells pre-treated with si MVP, si $v P A R P$ and control cells (used cell lines: WIPR, LoVo/Dx, WITR, and A2780TR) were seeded at a density of 4000 cells/well in 96-well plates. The cells were treated with drugs for $72 \mathrm{~h}$. The data are expressed as the mean values $\pm S D$ s from three independent experiments; ${ }^{*} p<0.05$, * $p<0.06$.

demonstrated that vPARP silencing decreased the viability of W1TR and A2780TR cells, but none of these effects were statistically significant.

Effects of knockdown of vault particles on MDR protein expression. To analyse the MDR protein expression under the condition of MVP or vPARP silencing western blot experiments were conducted.

Part A of Figure 5 presents the results for LoVo/Dx cells. In these cells, MVP silencing induced Pgp expression compared to the controls, but si vPARP induced no change in Pgp expression. Part B shows that the MVP silencing in W1PR cells decreased Pgp expression. The A2780TR cell line was analysed in a similar manner (Part C, Figure 5). In the A2780TR cells, no decrease in BCRP expression was noted after MVP and vPARP silencing.

Part D of Figure 5 describes the results for W1TR cells when we applied at similar conditions to other cell lines. The

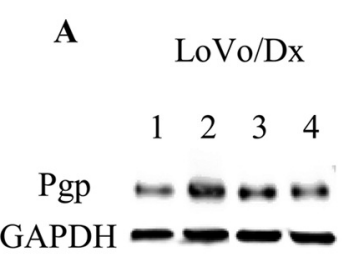

1. LoVo/Dx control

2. LoVo/Dx si MVP

3. LoVo/Dx control

4. LoVo/Dx si vPARP

C

A2780TR

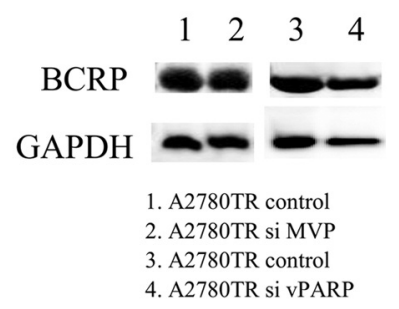

B

W1PR
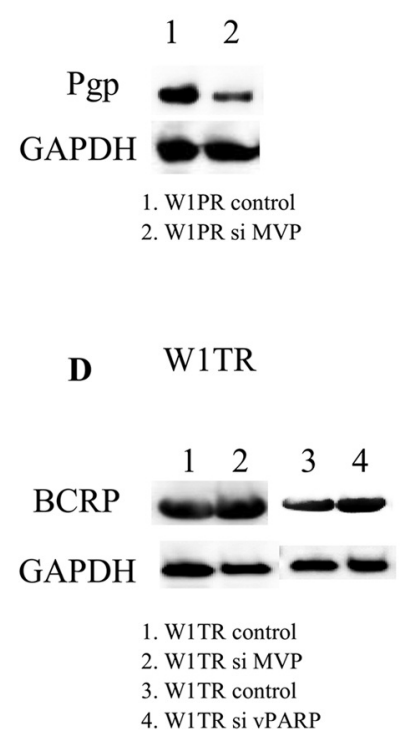

D W1TR

Figure 5. Effects of knocking-down of MVP and $v$ PARP on MDR protein expression in the LoVo/Dx, W1PR, A2780TR and WITR cell lines. Cellular proteins were separated on a 4-20\% mini-PROTEAN ${ }^{\circledR} T G X^{T M}$ precast gel and were transferred to a nitrocellulose membrane. The membrane was blocked and immunoblotted with a primary $A b$ and then an HRP-conjugated secondary Ab. Part A. Pgp expression in LoVo/Dx cells. Part B. Pgp expression in W1PR cells. Part C. BCRP expression in A2780TR cells. Part D. BCRP expression in WITR cells. GAPDH was used as a loading control for the western blots.

MVP silencing in W1TR cells did not have any significant influence on BCRP expression. The knocking-down of vPARP in W1TR cells significantly increased BCRP expression.

\section{Discussion}

In this research, we wanted to determine whether any relationship exists between MDR and vault proteins in cancer cells. Our intent was to demonstrate that disturbances in expression and MDR activity led to an increase in the expression and activity of vaults.

In the first part of this article, we demonstrated the higher expression of MVP and vPARP in the LoVo/Dx cell line compared to a drug-sensitive cell line, which suggested that these two proteins are important in drug resistance. The literature has also claimed that vaults are implicated in the transport of various substrates, including cytotoxic drugs (8, 28 ). In the ovarian cancer cell line W1PR, we noted that only MVP could be important in drug resistance because western blot analysis demonstrated the presence only of this protein 
in cells, which was consistent with clinical studies that showed a higher frequency of LRP/MVP expression in cancer specimens (14). The current experiment showed no expression of any protein component of vaults in the cell lines characterized by Pgp overexpression. This finding suggested that TUN caused full degradation of vaults. However, it was shown that sizable glycan was not attached to this molecule (29). In contrast, some recent data showed that MVP was post-translationally modified via oxidation (30), so it is possible that there are other modifications which we do not yet know and which TUN could destroy. The disappearance of MVP could not be directly induced by TUN because this is a long-lived protein with a half-life of at least three days (31), so the time of incubation with TUN in our experiment could be sufficient to deprive the cell of the protein completely. We suspected that TUN changed the activity of another unknown mechanism necessary for vault expression. The disappearance of MVP could be connected to MVP being a substrate for poly(ADP)-ribosylation conducted by vPARP (32), and TUN blocked this process, so we could not see any vault compartments in W1PR cells. In the A2780TR cell line, we noted that BCRP degradation and blocking glycosylation increased vPARP expression. This result suggested the importance of vPARP in drug resistance. This type of mechanism was observed before, where the increased expression of xenobiotic pumps occurred secondary to the failure of another defence mechanism (28). In the W1TR cell line, we noted significant decreases in MVP, TEP1 and vPARP expression after CAS treatment, which was correlated with a decrease in BCRP pump activity (18). This finding suggested that vaults and MDR participate in drug resistance simultaneously, similar to the results of Meijer et al. in adenomas, in which the increased expression of Pgp was correlated with increased expression of MVP (28) and those of Michieli et al. (33). Because this result was noted only in the W1TR cell line, it could indicate that $\mathrm{BCRP}$ and vault correlation is cell line-dependent.

We then analyzed the effectiveness and durability of the knocking-down of vault particles. This step was very important for the subsequent experiments. We showed that the siRNAs that we used to knock down MVP and vPARP were efficient in all of the cell lines, and its effects were stable four and seven days after silencing. Furthermore, in these examples, we noted that knocking down vPARP influenced the downregulation of MVP expression, which suggested that expression of the second protein was correlated with the presence of the first. However, Mossink et al. showed the opposite result, with the knock out of MVP resulting in dramatically lowered cellular vPARP levels (34). We suggested that MVP was sufficient in activity only in the simultaneous presence of vPARP in cell. Proof of this suggestion is that the mere expression of MVP in vaultlacking insect cells was sufficient for the assembly of vault- like particles (10). Mossink et al. claimed that the presence of MVP strongly enhanced the half-life of vPARP (34), so we believed that this mechanism might function in reverse. Unfortunately, si TEP1 was found to be ineffective and unspecific. For this reason, we did not use this siRNA for further analysis.

Next, we checked whether the knocking down of vault proteins had any effect on cell viability. We showed that the knockdown of MVP significantly influenced cell viability only in the W1PR cells. This finding demonstrated that MVP could participate in multidrug resistance in W1PR cells. Schroeijers et al. also showed that the addition of polyclonal anti-MVP during MO-DC culture led to reduced viability (35). Furthermore, we showed that the knockdown of MVP in W1PR led to the decreased expression of Pgp, which also could have contributed to the reduction of cell viability. These findings indicate that Pgp and MVP worked together on drug resistance in the W1PR cell line. This hypothesis was similar to that of Siva et al., who claimed that both vaults and other proteins involved in MDR might be sufficient to confer drug resistance, compared with MVP alone (36). No changes in cell viability were noted for the other cell lines after MVP silencing. In our opinion, it cannot be excluded that MVP is important in resistance mechanisms, and its knock down leads to the activation of other mechanisms connected with MDR. For this reason, the cells retained "the balance in keeping the resistance", so we could not determine the changes in cell viability after si MVP was used. When we knocked down vPARP, we observed that all of the tested cell lines became more sensitive to cytostatic drugs by at least two-fold, suggesting a significant role for this protein in drug resistance mechanisms. We know that vPARP could ADP-ribosylate MVP (10), and it is likely that the absence of this process could influence the total vault activity in drug resistance. Conversely, vPARP is not limited to associating with vaults (36), so its role in MDR could be indirect. Furthermore, when we compared MTT results with control western blots regarding the efficiency of siRNA, we thought that decreased cell viability after the use of si vPARP could be correlated with simultaneous partial blocking of MVP expression, so MVP could not be active in resistance mechanisms without the presence of vPARP. The transfection studies performed by Kichoefer et al. further confirmed our theory. They showed that the overexpression of MVP cDNA alone was not sufficient to confer a drug-resistant phenotype (8). Similar results were obtained by Scheffer et al., showing that MVP alone did not confer drug resistance in the A2780 cell line (37). This could be supported by the finding that vaults played roles in resistance (38) because these structures were created only in the presence of MVP, and MVP could not be substituted by another protein (34). If we assume that expression of MVP is p53 dependent (39), it could explain 
the decreased viability in si MVP cells, based on low p53 level expression.

Taken together, these findings showed that vPARP was not in itself significant in drug resistance. We did not agree with Mossink's team that, in the absence of MVP, the remaining vault components might still interact and possibly fulfil a functional role (34).

\section{Conclusion}

In conclusion, in our opinion, MVP is important in the drug resistance of cancer cells, but it requires the presence of vPARP for full activity. The absence of vPARP expression reduced MVP levels in cells. This component seemed to be a limiting factor for the functional formation of vaults and the possible acquisition of drug resistance. This finding suggested that only when those proteins are joined to each other and create vaults can they participate in resistance mechanisms. However, we still do not know whether this activity is direct or indirect, and it could be connected to MVP being a substrate for poly(ADP)-ribosylation by vPARP. Furthermore, we showed that, in cells, there is a correlation between multidrug resistance mechanisms connected to MDR and vaults. It could be possible that experiments in vitro show a different mechanism than that which exists in vivo.

\section{Conflicts of Interest}

The Authors declare that they have no competing interests.

\section{Acknowledgements}

This work was supported by Poznan University of Medical Sciences 502-14-02229373-10079.

\section{References}

1 Casanas A, Guerra P, Fita I and Verdaguer N: Vaults particles: a new generation of delivery nanodevices. Curr Opin Biotechnol 23: 972-977, 2012.

2 Rome L, Kedersha $\mathrm{N}$ and Chugani D: Unlocking vaults: organelles in search of a function. Trends Cell Biol 1: 47-50, 1991.

3 Kong LB, Siva AC, Rome LH and Stewart PL: Structure of vaults, a ubiquitous cellular component. Structure 6: 371-379, 1999.

4 Querol-Aidi J, Casanas A, Uson I, Leque D, Caston JR, Fita I and Verdaguer $\mathrm{N}$ : The mechanism of vault opening from the high resolution structure of the $N$-terminal repeats of MVP. The EMBP Journal 28: 3450-3457, 2009.

5 Berger W, Steiner E, Grusch M, Elbling L and Micksche M: Novel roles in signaling pathways regulation and immunity. Cell Mol Life Sci 66: 43-61, 2009.

6 Tanaka $\mathrm{H}$ and Tsukihara T: Structural studies of large nucleoprotein particle, vaults. Proc Jpn Acad 88: 416-433, 2012.
7 Kadersha NL and Rome LH: Isolation and characterization of a novel ribonycleoprotein particle: large structures contain a single species of small RNA. J Cell Biol 103: 699-709, 1986.

8 Kickhoefer VA, Rajavel KS, Scheffer GL, Dalton WS, Scheper RJ and Rome LH: Vaults are up-regulated in multidrugresistance cancer cell lines. J Biol Chem 273(15): 8974-1998, 1996.

9 Zon A, Mossink MH, Scheper RJ, Sonneveld P and Wiemer EAC: The vault complex. Cell Mol Life Sci 60: 1828-1837, 2003.

10 Mossink MH, Zon A, Scheper RJ, Sonneveld P and Wiemer EAC: Vaults: a ribonucleoprotein particle involved in drug resistance? Oncogene 22: 7458-7467, 2003.

11 Amort M, Nachbauer B, Tuzlak S, Kieser A, Schepers A, Villunger $\mathrm{A}$ and Polacek $\mathrm{N}$ : Expression of the vault RNA protects cells from undergoing apoptosis. Nat Commun 6: 7030, 2015.

12 Yang J, Kickhoefer VA, Ng BC, Gopal A, Bentolila LA, John S, Tolbert SH and Rome LH: Vaults are dynamically unconstrained cytoplasmic nanoparticles capable of half vaults exchange. ACS Nano 4: 7229-7240, 2010.

13 Herlevsen M, Oxford G, Owens CR, Conaway M and Theodorescu D: Depletion of major vault protein increases doxorubicin sensitivity and nuclear accumulation and disrupts its sequestration in lysosomes. Mol Cancer Ther 6(6): 18041813, 2007.

14 Izquierdo MA, Scheffer GL, Schroeijers AB, de Jong MC and Scheper RJ: Vault-related resistance to anticancer drugs determined by the expression of the major vault protein LRP. Cytotechnology 27: 137-148, 1998.

15 Navarro L, Gil-Benso R, Megías J, Muñoz-Hidalgo L, SanMiguel T, Callaghan RC, González-Darder JM, López-Ginés C and Cerdá-Nicolás MJ: Alteration of major vault protein in human glioblastoma and its relation with EGFR and PTEN status. Neuroscience 297: 243-251, 2015.

16 Chugani DC, Rome LH and Kadersha NL: Evidence that vault ribonucleoprotein particles localize to the nuclear pore complex. J Cell Sci 106: 23-29, 1993.

17 Wojtowicz K, Januchowski R, Nowicki M and Zabel M: Inhibition of protein glycosylation reverses the MDR phenotype of cancer cell lines. Biomed Pharmacother 4: 49-56, 2015.

18 Wojtowicz K, Januchowski R, Sosińska P, Nowicki M and Zabel M: Effect of brefeldin A and castanospermine on resistant cell lines as supplements in anticancer therapy. Oncol Rep 35: 28962906, 2016.

19 Sharom FJ: ABC multidrug transporters: structure, function and role in chemoresistance. Pharmacogenomics 9: 105-127, 2008.

20 Pastan I and Gottesman MM: Multiple-drug resistance in human cancer. N Eng J Med 316: 1388-1393, 1987.

21 Wojtowicz K, Szaflarski W, Januchowski R, Zawierucha P, Nowicki $\mathrm{M}$ and Zabel $\mathrm{M}$ : Inhibitors of $N$-glycosylation as a potential tool for analysis of the mechanism of action and cellular localisation of glycoprotein P. ABP 59: 445-450, 2012.

22 Noguchi K, Katayama K and Sugimoto Y: Human ABC transporter $\mathrm{ABCG} 2 / \mathrm{BCRP}$ expression in chemoresistance: basic and clinical perspectives for molecular cancer therapeutics. Pharmgenomics Pers Med 7: 53-64, 2014.

23 Nakagawa H, Wakabayashi-Nakao K, Tamura A, Toyoda Y, Koshiba S and Ishikawa T: Disruption of $N$-linked glycosylation enhances ubiquitin-mediated proteasomal degradation of the 
human ATP-binding cassette transporters ABCG2. FEBS J 276: 7237-7252, 2009.

24 Januchowski R, Wojtowicz K, Sujka-Kordowska P, Andrzejewska M and Zabel M: MDR Gene Expression Analysis of Six Drug-Resistant Ovarian Cancer Cell Lines. Biomed Res Int 2013: 241763, 2013.

25 Januchowski R, Zawierucha P, Andrzejewska M, Ruciński M and Zabel M: Microarray-based detection and expression analysis of ABC and SLC transporters in drug-resistant ovarian cancer cell lines. Biomed Pharmacother 67(3): 240-245, 2013.

26 Januchowski R, Zawierucha P, Ruciński M, Andrzejewska M, Wojtowicz $\mathrm{K}$, Nowicki $\mathrm{M}$ and Zabel $\mathrm{M}$ : Drug transporter expression profiling in chemoresistant variants of the A2780 ovarian cancer cell line. Biomed Pharmacother 68(4): 447-53, 2014.

27 Szaflarski W, Sujka-Kordowska P, Januchowski R, Wojtowicz $\mathrm{K}$, Andrzejewska $\mathrm{M}$, Nowicki $\mathrm{M}$ and Zabel $\mathrm{M}$ : Nuclear localization of $\mathrm{P}$-glycoprotein is responsible for protection of the nucleus from doxorubicin in the resistant LoVo cell line. Biomed Pharmacother 67(6): 497-502, 2013.

28 Meijer GA, Schroeijers AB, Flens MJ, Meuwissen SG, van der Valk P, Baak JP and Scheper RJ: Increased expression of multidrug resistance related proteins PGP, MRP1, and LRP/MVP occurs in colorectal carcinogenesis. J Clin Pathol 52: 450-454, 1999.

29 Scheper RJ, Broxterman HJ, Scheffer GL, Kaaijk P, Dalton WS, van Heijningen TH, van Kalken CK, Slovak ML, de Vries EG, van der Valk P, Meijer CJLM and Pinedo HM: Overexpression of a $\mathrm{Mr} 110,000$ vesicular protein in non-P-Glycoproteinmediated multidrug resistance. Cancer Research 53: 1475-1479, 1993.

30 Das D, Wang YH, Hsieh CY and Suzuki TJ: Major vault protein regulates cell growth/survival signaling through oxidative modifications. Cellular Signalling 28: 12-18, 2016.

31 Zheng CL, Sumizawa T, Che XF, Tsuyama S, Furukawa T, Haraguchi M, Gao H, Gotanda T, Jueng HC, Murata F and Akiyama S: Characterization of MVP and VPARP assembly into vault ribonucleoprotein complexes. Biochem Biophy Res Commun 326: 100-107, 2004.
32 Kichoefer VA, Siva AC, Kedersha NL, Inman EM, Ruland C, Streuli M and Rome LH: The $193-\mathrm{kD}$ vault protein, VPARP is a novel poly(ADP-ribose) polymerase. J Cell Biol 146: 917-928, 1999.

33 Michieli M, Damiani D, Ermacora A, Raspadori D, Michelutti A, Grimaz S, Fanin R, Russo D, Lauria F, Masolini P and Baccarani M: P-glycoprotein (PGP) and lung resistance-related protein (LRP) expression and function in leukaemic blast cells. Br J Haematol 96: 356-365, 1997.

34 Mossink MH, van Zon A, Fränzel-Luiten E, Schoester M, Kickhoefer VA, Scheffer GL, Scheper RJ, Sonneveld P and Wiemer EA: Disruption of the murine major vault protein (MVP/LRP) gene does not induced hypersensitivity to cytostatics. Cancer Res 62: 7298-7304, 2002.

35 Schroeijers AB, Reurs AW, Scheffer GL, Stam AG, de Jong MC, Rustemeyer T, Wiemer EA, de Gruijl TD and Scheper RJ: Upregulation of drug resistance-related vaults during dendritic cell development. J Immunol 168(4): 1572-1578, 2002.

36 Siva AC, Raval-Fernandes S, Stephen AG, LaFemina MJ, Scheper RJ, Kickhoefer VA and Rome LH: Up-regulation of vaults may be necessary but not sufficient for multidrug resistance. Int J Cancer 92: 195-202, 2001.

37 Scheffer GL, Wijngaard PL, Flens MJ, Izquierdo MA, Slovak ML, Pinedo HM, Meijer CJ, Clevers HC and Scheper RJ: The drug resistance-related protein LRP is the human major vault protein. Nat Med 1(6): 578-582, 1995.

38 Szaflarski W, Sujka-Kordowska P, Pula B, Jaszczyńska-Nowinka $\mathrm{K}$, Andrzejewska M, Zawierucha P, Dziegiel P, Nowicki M, Ivanov $\mathrm{P}$ and Zabel M: Expression profiles of vault components MVP, TEP1 and vPARP and their correlation to other multidrug resistance proteins in ovarian cancer. Int J Oncol 43: 513-520, 2013.

39 An HJ, Ryu SJ, Kim SY, Choi HR, Chung JH and Park SC: Age associated high level of major vault protein is p53 dependent. Cell Biochem Funct 27(5): 289-295, 2009.

Received April 29, 2017

Revised May 12, 2017

Accepted May 15, 2017 